\title{
Examining Salient Dimensions of Online Shopping and the Moderating Influence of Gender: The Case of Students at a South African University
}

\author{
Mercy Makhitha \\ Senior Lecturer: Department of Logistics, Vaal University of Technology, Private Bag X021, Vanderbijlpark, 1900 \\ Email:mercym@vut.ac.za \\ Nobukhosi Dlodlo \\ Lecturer: Department of Marketing and Sport Management, Faculty of Management Sciences \\ Vaal University of Technology, Private Bag X021, Vanderbijlpark, 1900 \\ Email: nobukhosid@vut.ac.za
}

Doi:10.5901/mjss.2014.v5n23p1838

\begin{abstract}
Online shopping is still in its infancy in South Africa. This is despite the fact that Internet penetration has increased tremendously in the country owing to increased Broadband access combined with the speed of wireless connectivity. Online shopping sales in South Africa are estimated at over R2bn. However, since students are more active on the Internet, they are considered the potential dominant users of online shopping. Thus, it is important for marketers to understand the dimensions that influence students' online shopping behaviour. In addition, the moderating influence of gender is an important biographical consideration in technology adoption research. A survey was conducted among university students with a view to determine the dimensions that influence the uptake of online shopping. An adapted questionnaire was designed to cover a plethora of online shopping dimensions. The majority of students in the sample were undergraduate females. The findings of the study revealed that students value the convenience of the online shopping experience. Security was also a major consideration for female rather than male consumers, when opting to conduct shopping activities online. Albeit, the results of the independent $t$ tests revealed significant differences along the security dimension only $(p<0.05)$. However, significant differences could not be established along other dimensions that were identified in the study such as convenience, ease of use and perceived benefits. Notwithstanding this fact, this study provides a bedrock for cumulative research on the salience of online shopping within a student community. In addition, a clear understanding of the shopping behaviour of tertiary students can provide opportunities for designing new capabilities that will support value-based online shopping activities.
\end{abstract}

Keywords: online shopping; convenience; security; ease of use; benefits

\section{Introduction}

The Internet represents a new era in which many of the traditional marketing conventions are broken (Chaston, 2000). Coupled with that, the digital revolution has brought about a paradigmatic shift in the manner in which consumers perform business transactions (Hsiao, 2009). As such, the online platform is nearly a perfect market for performing dealings because information is instantaneous and buyers can easily compare the offerings of a variety of sellers globally (Ward, 2008; Huang, 2000). For businesses, the key to survival in the future depends on how well they can integrate this medium in their business models today. In order to sell anything over the Internet, firms have to take into account who their customers are, what their spending habits are like, as well as the products and services they prefer, while shopping along electronic platforms (Richa, 2012). Online shopping may be considered a dynamically continuous innovation because it has had a significant effect on consumption patterns by modifying and improving the existing shopping behaviour (Molesworth \& Suortti 2001). It appears then that Internet-based shopping has reshaped consumers' habits and has caused far-reaching vicissitudes to the distribution channel.

Online shopping may be defined as the process whereby consumers directly buy goods or services from a seller in real-time (the level of Internet responsiveness that is judged as sufficiently immediate) without the use of a traditional intermediary service (Hsiao, 2009). It is evaluated often as a form of electronic commerce (e-commerce) which utilises an online shop, commonly referred to as e-shop, e-store, web-store or web-shop (Shelly, Cashma, \& Vermaat, 2008). Generally, merchants sell products and services directly to consumers while in e-commerce or electronic retailing (e- 
tailing), the web channel is used to conduct business and also to sell products and services (Shelly, Cashma \& Vermaat 2008). The idea is not only just about disseminating information, but also about building customer relationships and realising company profits (Falk, Sockel, \& Chen 2005).

An online shop evokes the physical analogy of buying products or services at a brick-and-mortar retailer or in a shopping centre. Therefore, business-to-consumer (B2C) based e-commerce capacitates the consumer to purchase products and services online using Internet technologies and associated infrastructure (Pavlou, 2003). In some cases, consumers may use online shopping parallel to alternative retail channels such as retail stores, catalogues, mail order or TV shopping, often termed multi-channel shopping (Ward, 2008).

Approximately, 85 percent of the world's online population has ordered goods over the Internet during recent years, and online shoppers accounted for over 40 percent of the adult population in Japan, Norway, the United Kingdom, South Korea, the Netherlands, Denmark and Australia (Nielsen Media Research Report, 2008; OECD, 2008). However, only 11.5 percent of South Africa's population makes use of the Internet. Moreover, the largest online retailers in South Africa represent less that 1 percent of the country's total income for the retail trade industry of R486 billion (Statistics South Africa, 2010). This indicates that online shopping is still in its infancy in South Africa.

The net worth of online retailing sales was estimated to be at R2.26 billion in 2012, which contributes 0.36 percent to the total South African retail (Pillay et al., 2012). The MasterCard Worldwide Online Shopping Survey reported that the proportion of South African Internet users shopping online grew to 58 percent in 2012, up from 53 percent in 2010, and 44 percent in 2009 (Planting, 2012). The findings of the report also indicated that consumers are no longer confined to purchasing digital books, entertainment, plane tickets and mobile phone applications, but are increasingly expanding their online shopping usage to include grocery purchases (38\%), clothing purchases (34\%), as well as the purchases of personal care products (20\%) on popular web stores such as Kalahari.com. The increased prevalence of Internetenabled, wireless, hand-held devices such as smartphones, tablets, notebooks and personal digital assistants, has propelled this trajectory. Furthermore, the arrival of PayPal, an online payments system, in 2010 has helped to encourage growth within the e-commerce market. Relatedly, economic globalisation, driven by deregulation and the pervasive use of information technologies, has opened up new inescapable channels for fashion retailers (Moodley, 2003). Therefore, it may be inferred that the Internet has become a key enabler for a networked retail economy.

\subsection{Determinants of user acceptance of online shopping}

When consumers decide to shop online, several factors determine whether they will continue using the selected e-tailer or not. Studies of Chen and Macredie (2005) indicate that ease of use and the presence of user-friendly features are paramount to a consumer's decision to shop online. This notion is further substantiated by Campbell (1988) and Clemes, Gan and Zhang (2014) who demonstrate that less-complex websites such as those with attributes, elements and features that support users with varying levels of Internet proficiency, are potential sources of impulse purchases. However, novelties in the form of innovative graphics on the site have been proven to be irreplaceable when it comes to encouraging online store visits, browsing, and inadvertent consumption of various products and services on the online platform (Verhagen, Boter, \& Adelaar, 2010; Huang, 2000; O'Cass \& Fenech, 2003).

Consumers are repeatedly time-pressed, and want more convenience-oriented, value-added services that will save them time. Online stores have been hailed for their ubiquitous nature, as they are available 24 hours a day for the convenience of the consumers (Ward, 2008). They provide relief to consumers by eliminating travel necessity, time and effort (Ali, Sankaran \& Stevrin, 2010). Alreck and Settle (2002) note, that the efficient use of time was a critical issue for the modern time-scarce consumer. Therefore, online shopping can be viewed as a time saver for both the shopper and the buyer, as it can eliminate trips to the store and the long lines and delays when at the store. The majority of consumers choose online shopping for a faster and more efficient shopping experience that can be conducted in the comfort of their own homes (Liang, 2009). Additionally, online retailers are providing more channel variations that bring them into direct contact with the consumer without the shopper stepping into the physical store, such as mobile phones and smart televisions (Smith et al., 2013). Thus, online shopping services have the potential to fulfill the goals of both consumers and online retailers (Prasad \& Aryasri, 2009).

The unlimited access to competitive pricing across various web stores (Ward, 2008), combined with the availability of a broader selection of products and services, is a major consideration for consumers who decide to shop online (De Swardt \& Wagner, 2008; Jarvenpaa \& Todd, 1997). A study by Huang (2000) highlights that greater access to product information tends to enrich the shopping environment within virtual market places. This factor corresponds with concept of Mehrabian and Russell (1974) regarding information load as the complex spatial measure of stimuli within a setting. On the other hand, the studies of Liang (2009), O'Cass and Fenech (2003), Childers, et al. (2001) and Eastin (2002) focused 
on personal perceived values as the underlying dimensions for online shopping involvement items that encapsulated perceived danger, perceived convenience, perceived website quality, as well as perceived benefits. Furthermore, Liao and Cheung (2001) described product life content (the degree to which the product is essential to the daily lives of its users) as being influential towards the consumer's decision to shop online.

Several scholars have highlighted the importance of website design factors as salient towards the uptake of online shopping by consumers. Variables included in this factor are security and privacy (Ranganathan \& Ganapathy, 2002; Ward, 2008). Perceived web security describes individual awareness of web security when providing and sending personal or financial information (O'Cass \& Fenech, 2003). Since buyers and sellers do not interact face-to-face, and the virtual environment allows for high anonymity, online shopping involves greater security concerns than conventional trading. Wolfinbarger and Gilly (2003) identify security as one of the four factors for measuring online retailer service quality. Meanwhile, O'Cass and Fenech (2003) express a similar opinion that user perceptions of web security influence their adoption of online shopping. Hasslinger, Hodzic and Opazo (2007) maintain that trust and security factors are a major influence for the consumers when considering a potential purchase on the Internet platform. Elements that encourage consumers to purchase various products online include web page design, ease of navigation and the searching for information, security guarantees and clearly stated return policies (Siddiqui et al., 2003).

Other scholars have cited utilitarian or goal-oriented motivations for engaging in online shopping activities. Some of the most common utilitarian motivation factors influencing online shopping include perceived usefulness, which refers to the fact that a user believes in the existence of a positive use-performance relationship when deciding to shop online (Vijayasarathy, 2004). Ease of use was also identified in the literature as an underlying dimension for online shopping adoption, as it pertains to the extent to which a shopper believes that using an online system would be free of effort (Khare, Khare \& Singh, 2012). Other scholars also emphasise security and privacy (Ha \& Stoel, 2009; Hasslinger et al., 2007; Lian \& Lin, 2008 Vijayasarathy, 2004). Security concerns are a major drawback for online shopping intention (Wolfinbarger and Gilly, 2003; Ranganathan \& Ganapathy, 2002).

\subsection{Gender and online shopping factors}

Traditionally, shopping is an activity more favoured by women. It is women who are usually in charge of household shopping and who hold more positive attitudes towards the traditional store and catalogue shopping than their male counterparts (Alreck \& Settle, 2002). However, the new shopping channel provided by the Internet seems to result in a different, if not opposite, gender pattern. Although there was no significant difference between online shoppers and nonshoppers in terms of gender in previous studies (Brashear et al. 2010; Chiu, Lin \& Tang, 2005; Donth \& Garcia, 1999), men were found to make more purchases (Slyke, Comunale \& Belanger, 2002) and spend more money online (Venkatesh \& Morris, 2000) than women. As such, men's perceptions of online shopping were approximately the same or even more favourable than those of female consumers. Such a change of gender pattern in the online shopping environment has been explained using different models or factors, including shopping orientation (Rodgers \& Harris, 2003), information technology acceptance and resistance (Susskind, 2004; Vijayasarathy, 2004), product involvement (Garbarino \& Strahilevitz, 2004) and specific product properties (Verhagen et al., 2010; Lian \& Lin, 2008; Donthu \& Garcia, 1999).

First, shopping orientation was found to influence consumers' shopping activities, interests and opinions. Men were more convenience-oriented and less motivated by social interaction, while women were motivated by hedonism in their shopping decisions (Babin, Darden \& Griffin, 1994). However, the function of shopping online as a social activity is weak compared with shopping in traditional stores due to the lack of face-to-face interaction while operating on the online platform. Secondly, there are generalisations in the literature that indicate that women are more skeptical about ecommerce when compared to their male counterparts (Khare \& Rakesh, 2011). As such, women tend to be emotionally less satisfied with online shopping, and consequentially make fewer online purchases as compared to their male counterparts (Jen-Hung \& Yi-Chun, 2010; Hanson, 2010; Rodgers \& Harris, 2003). The findings support earlier research, which suggests that men have more positive attitudes towards online shopping, and therefore, are more likely to purchase products online (Hanson, 2010). On the other hand, women prefer to examine shopping products physically, as well as enjoying group shopping and window-shopping (Chou, Wu \& Chen, 2010). Consequently, women demonstrate a stronger need for tactile input in product evaluations than men (Venkatesh \& Morris, 2000). As such, the inability to touch or try on products, a shortcoming of online purchasing, might also result in fewer female online shoppers. This characteristic affects online purchase negatively, particularly for those products that require more tactile cues for their evaluation (for example, shoes and clothes).

However, the extant waves of empirical research on technology and gender are not conclusive, as existing gender 
differences may be a function of the different levels of socialisation and access to technology within a specific society (Cho \& Jialin, 2008). It is also possible that with time, any reported gender differences related to technology usage will cease to exist across global markets. Given the inconsistencies in the literature, online consumer behaviour has been examined from the perspectives of consumer demographics (Chou et al., 2010; Hanson, 2010; Alreck \& Settle, 2002; Venkatesh \& Morris, 2000; Donthu \& Garcia 1999). Moreover, the persistent gender imbalances existing in the South African consumer segment leading to significant variations in consumption decisions have been eminent. This is true within the South African context, which currently is suffering from the post-trauma of the apartheid legacy, and reeling from the problem of separateness. Thus, cumulative research on the online shopping behavioural differences between male and female students merited the authors' attention.

\section{Motivation for the Study}

It has been established that there is high growth in the amount of online retail sales globally with the Internet transforming as a substitute for traditional retail marketing formats (Siddiqui et al., 2003). Moreover, the online retail sector demonstrates signs of enormous competitiveness (Planting, 2012) and invariably contributes significantly to the South African economy (Statistics South Africa, 2010). However, although a trajectory in the high growth rate in online retailing is expected to continue, the current slow economic environment creates challenges for retailers to ensure that customers perceive sufficient justification to engage in further online shopping activities, especially among university students. Furthermore, since shopping online has very different characteristics from shopping in a brick-and-mortar store, some of these characteristics may contribute to consumers' decisions to shop online, while others may discourage them.

The most attractive market segment, the student consumer, has morphed to become the new target market for advertisers and marketers because of its increasing buying power (Koutras, 2006). Despite the fact that this market segment constitutes over 50 percent of the total population in South Africa, studies aimed at enhancing the online purchasing activity of this cohort are scant. Approximately, 90 percent of university students access the Internet daily (Chou et al., 2010). The exceptional levels of academic frustrations, coupled with sensation-seeking behaviour among a majority of tertiary students, have contributed to the Internet platform becoming a universal, social and business destination.

In addition, the low-cost financing of technological devices by student financial services such as EduLoan, has driven the influx of wireless devices into the student community. Generally, students demonstrate general liking towards purchasing, and have ample time for shopping, with a tendency to spend money freely, quickly and impulsively (Liang, 2009). As such, the university students form part of the global youth culture that transcends all boundaries and are part of the global village (Cant \& Machado, 2004). Therefore, the familiarity of students with the Internet, coupled with their emerging market power, and the likelihood of developing loyal customers by establishing initial retailer-customer ties, provided strong rationale for exploring this consumer group, and their behavioural intentions for online shopping. As such, the following research questions guided the study:

\subsection{Research questions}

RQ1: What are the underlying factors that influence online shopping acceptance among university students?

RQ2: What is the impact of gender, as a demographic characteristic, on online shopping acceptance among university students?

\section{Methodology}

To obtain an impartial perspective, a theoretical foundation was established initially through a literature review of online shopping dimensions. A quantitative research approach was followed in the current study, using the survey method. Survey methodology is accepted broadly, and has been used by numerous studies in past examinations of online shopping factors (Khare et al., 2012; Hanson, 2010; Chou et al., 2010). This descriptive survey employed an adapted questionnaire and statistical methods using Statistical Package for Social Sciences (SPSS) software, version 22.0, for Windows.

\subsection{Participants and sampling strategy}

A non-probability convenience sampling procedure was used to recruit respondents by selecting for inclusion only those 
subjects that are most accessible to the researchers (Malhotra, 2010). Convenience sampling was more appropriate for this study, as there was no way in which more formal access to lists and databases of online shoppers in South Africa could have been obtained. A student sample size of 300 was chosen for the study; consistent with that used by a number of scholars in similar studies (Khare et al., 2012; Khare \& Rakesh, 2011; Vijayasarathy, 2004). The rationale for selecting a student sample was that a large proportion of tertiary students spend a lot of time browsing online web stores and making repeat purchases of varying expanses (Chou et al., 2010). The target population comprised both male and female respondents of various age groups (18 years and older), who are actively involved in online purchases from various websites, because it is believed that they can offer valuable contributions to the study (Churchill \& lacobucci, 2002). To facilitate external validity of the study, only those users who had minimum experience ( $\geq 6$ months) with online purchases were included in the study. In addition, respondents younger than 18 and non-patrons of fashion retailer websites were considered non-eligible, and therefore, excluded from the study.

\subsection{Measuring instrument and data collection}

Since a few student-based studies that focused on online shopping were identified in the literature (Childers et al., 2001; Khare et al., 2012; Khare \& Rakesh, 2011; Kim, 2004; Vijayasarathy, 2004), it was not possible to identify a unidimensional instrument to measure online shopping factors. As such, the instrument utilised in the study contained measurement items derived from prior shopping motivation research (Childers et al., 2001; Khare et al., 2012; Khare \& Rekesh, 2011; Kim, 2004; Vijayasarathy, 2004). The items that were propounded by these scholars were adapted in the current study based on the trait-valid component measures and high discriminant validity in previous studies. This suggests that limited bias and errors may be expected. This provided further support for the internal consistency of the gleaned scales in the operationalisation and development of cumulative research focusing on online shopping within a South African context. While these scale items were developed specifically for online consumption in various contexts and settings, relevant modifications were made to the original variables used by these researchers in order to capture the holistic online shopping experiences of the respondents. The participants were provided with a list of 22 items and asked to rate their level of disagreement or agreement with each item on a five-point Likert scale, anchored between strongly disagree (1) and strongly agree (5). The questionnaire also contained a section on demographics, with variables relating to the gender, age and experience with online shopping. These questions were structured on dichotomous, interval and ranking-order closed-ended scales, respectively.

Five lecturers were identified as primary contacts at the university and were further provided with training, which enabled them to assume the role of research assistant/s by facilitating the data collection procedure during normal classes. Out of the 300 questionnaires that were distributed, 290 questionnaires were returned. Among these, 34 questionnaires were discarded because of incorrect completion of the questionnaire, or too many fields of data missing. This culminated in an eventual sample of 256 usable questionnaires, giving a response rate of 85 percent.

\subsection{Reliability and validity}

The reliability assessment for the social media instrument was ascertained by computing the Cronbach alpha coefficient values, as shown on Table 1. According to Nunnally (1978), Cronbach alpha coefficients of less than 0.50 are deemed unacceptable, those between 0.50 and 0.69 are considered as being adequate, whereas those above 0.70 are regarded as being acceptable in social science enquiry. The sub-scale reliability values ranged between 0.598 and 0.784 , while the standardised Cronbach alpha value for the entire scale was established at 0.785 , indicating an acceptable level of internal consistency among the scale items.

Table 1: Cronbach alpha values for the online shopping factors

\begin{tabular}{lccc}
\hline Dimension/Construct & N & Number of Items & Cronbach Alpha \\
\hline Perceived convenience (PC) & 256 & 5 & .784 \\
Perceived security (PS) & 256 & 5 & .773 \\
Perceived ease of use (PEOU) & 256 & 4 & .734 \\
Perceived benefits (PB) & 256 & 3 & .598 \\
\hline Overall Cronbach alpha coefficient for the entire scale $=.785$ & & \\
\hline
\end{tabular}

Content validity is the representativeness of the content of the measurement instrument (Malhotra, 2010). The 
questionnaire was pilot-tested with a sample of 30 conveniently selected respondents in order to check the wording, phrasing and language appropriateness of the questionnaire items. Exploratory factor analysis was conducted with a view to establish construct validity of the scale. The factor structure showed absence of cross-loadings, thus providing evidence of discriminant validity (items loading on each construct were theoretically dissimilar from those loading on the other constructs) as suggested by Zikmund and Babin (2007). Subsequently, the items loading on an individual construct theoretically were related to each other, demonstrating high convergent validity (correspondence of items loading on one factor only). Furthermore, the reliability of the scale, as measured by coefficient alpha, reflects the degree of cohesiveness among the scale items is an indirect indicator of convergent validity (Nunnally \& Bernstein, 1994).

\subsection{Data analysis}

The data were analysed using SPSS.

\subsection{Sample composition}

The sample composition consisted of the majority of females, represented by 54 percent ( $N=140)$. Similarly, the modal age cohort in the student sample was 18-21 years $(51 \%, \mathrm{~N}=132)$. Approximately, 82 percent of the students were undergraduates, while the majority of the respondents $(62 \%, \mathrm{~N}=159)$ purported to having experience with online shopping for over three years. However, the majority of the students do not shop online $(87.9, \mathrm{~N}=226)$. Table 2 despicts these results.

Table 2: Demographic profile of the respondents (online shoppers)

\begin{tabular}{|c|c|c|c|c|}
\hline Variable & Categories & Population (N) & Sample Frequency (n) & Percentage (\%) \\
\hline Gender & $\begin{array}{l}\text { Males } \\
\text { Females }\end{array}$ & $\begin{array}{l}256 \\
256\end{array}$ & $\begin{array}{l}118 \\
138\end{array}$ & $\begin{array}{l}46 \\
54\end{array}$ \\
\hline Age & $\begin{array}{l}\text { Between } 18-21 \text { years } \\
\text { Between } 22-25 \text { years } \\
\text { Over } 25 \text { years }\end{array}$ & $\begin{array}{l}256 \\
256 \\
256\end{array}$ & $\begin{array}{c}132 \\
102 \\
22\end{array}$ & $\begin{array}{c}51 \\
40 \\
9\end{array}$ \\
\hline Length of time with Internet access & $\begin{array}{l}\text { Less than one year } \\
\text { Between 2-3 years } \\
\text { More than } 3 \text { years }\end{array}$ & $\begin{array}{l}256 \\
256 \\
256\end{array}$ & $\begin{array}{c}43 \\
54 \\
159\end{array}$ & $\begin{array}{l}17 \\
21 \\
62\end{array}$ \\
\hline Shop online: & $\begin{array}{l}\text { Yes } \\
\text { No }\end{array}$ & $\begin{array}{l}256 \\
256\end{array}$ & $\begin{array}{c}31 \\
226\end{array}$ & $\begin{array}{l}12.1 \\
87.9\end{array}$ \\
\hline
\end{tabular}

\subsection{Exploratory factor analysis}

Data were analysed using SPSS (Field, 2005). Exploratory factor analysis was carried out with a view to condensing the experimental variables into identifiable factors. The principal component analysis method was utilised, while the rotation method was Varimax rotation, with Kaiser normalisation converged in six iterations. Selection of this orthogonal rotation method with Kaiser normalisation was aimed at producing factors that are uncorrelated, leading to high factor interpretability. The Bartlett's test was significant at $p<0.000$, implying that the data set is not an identity matrix with zero correlations (inter alia variables are correlated), thus confirming that a factor analysis procedure could be applied in the study. Moreover, the Bartlett's test produced a chi square value $\left(x^{2}\right)$ of 1670.798 , and a KMO value of 0.806 (>0.50), further confirming the appropriateness of the data set for factor analysis.

Several default measures were employed in the factor extraction procedure for this study. In line with Zikmund and Babin (2007), the default measure was to use the eigen value ( $\geq$ than 1) criteria, and the percentage total variance contribution that is considered significant. In addition, factor loadings ( $\geq 0.50)$, percentage of variance explained, and the scree plot criterion guided the extraction of factors. The total variance explained by the extracted factors was 51 percent, indicating that the other 49 percent is accounted for by extraneous variables that do not constitute part of this study and may be investigated in the future. Furthermore, upon developing the scree plot, four data points were observed above the natural bend or break point along the curve. A threshold of 0.4 to 0.70 was maintained on the communalities, as well as a cut-off point of 0.30 on the item-to-total correlations, as guided by Kim and Mueller (1978). Resultantly, five items were dropped from factor analysis after they loaded unsatisfactory in the initial scale refinement procedure, suggesting that those items may be incapable of differentiating between factors. This procedure resulted in the extraction of a clear four- 
factor structure. These factors were labelled perceived convenience, perceived security, perceived ease of use and perceived benefits, respectively. Table 3 shows the results of the rotated factor analysis procedure and the resultant psychometric properties of the scale.

Table 3: Factor loading matrix and psychometric properties of the scale

\begin{tabular}{|c|c|c|c|c|}
\hline \multicolumn{5}{|c|}{ Rotated Component Matrix } \\
\hline & \multicolumn{4}{|c|}{ Component } \\
\hline & Factor 1 & Factor 2 & Factor 3 & Factor 4 \\
\hline Factors and variable description & \begin{tabular}{|c|}
$\begin{array}{c}\text { Perceived } \\
\text { convenience }\end{array}$ \\
\end{tabular} & $\begin{array}{l}\text { Perceived } \\
\text { security }\end{array}$ & $\begin{array}{l}\text { Perceived } \\
\text { ease of use }\end{array}$ & $\begin{array}{c}\text { Perceived } \\
\text { benefits }\end{array}$ \\
\hline Online shopping saves time driving from store to store & .834 & .090 & .085 & \\
\hline I can order products from distant places & .823 & & .071 & .068 \\
\hline I can purchase products at any time of the day & .755 & .056 & .202 & .195 \\
\hline Online shopping enable (can) me to do my shopping quickly & .579 & & .277 & .097 \\
\hline Online shopping is a good idea & .505 & & .052 & .114 \\
\hline My credit card information may be stolen ${ }^{\star}$ & -.065 & .856 & & \\
\hline Quality of products delivered may not be the same as one ordered* & -.056 & .767 & -.106 & .105 \\
\hline My personal information may not be safe when shopping online* & -.036 & .692 & .098 & -.050 \\
\hline It can be difficult to return the defective product* & .139 & .686 & -.173 & \\
\hline I have to wait for goods to be delivered* & .225 & .581 & .135 & -.137 \\
\hline I am interested in shopping online & .067 & -.114 & .165 & .089 \\
\hline I often consider shopping online & .100 & & .156 & .119 \\
\hline I will use online shopping in future & & & .131 & .113 \\
\hline I think I can shop online without any need for assistance & .132 & .035 & .757 & .031 \\
\hline I think Internet shopping requires less effort on my part & .183 & & .713 & .219 \\
\hline I think I can shop online without encountering any problems & .057 & -.037 & .709 & .059 \\
\hline I think Online shopping is easy to use & .144 & -.076 & .645 & .163 \\
\hline I can get better prices & .196 & & .220 & .753 \\
\hline I can find greater variety of products and models online & & -.084 & .111 & .706 \\
\hline Online shopping makes it easy to compare various products ad brands & .246 & .043 & .088 & .595 \\
\hline$\%$ of variance explained per factor & 23.62 & 14.11 & 7.60 & 5.75 \\
\hline Cumulative $\%$ of variance & 23.62 & 37.73 & 45.33 & 51.08 \\
\hline Factor reliability (Cronbach's Alpha a) & 0.78 & 0.77 & 0.73 & 0.59 \\
\hline Eigen values & 4.725 & 2.823 & 1.522 & 1.1150 \\
\hline
\end{tabular}

\section{Results and Discussion}

The first factor, perceived convenience (eigenvalue $=4.725$ ), explained 23.6 percent of the total post-rotation variance. In addition, high factor loadings were obtained on this sub-scale (.505 $\leq P C$ factor loadings $\leq .834)$ as well as high communalities (.434 $\leq P C$ communalities $\leq .717)$, thus confirming the internal validity of the factor. Five items loaded on this construct, namely 'online shopping saves times driving from store to store' ( $\bar{x}=4.31$ ), 'I can order products from distant places' ( $\bar{x}=4.42)$, 'I can purchase products at any time of the day' ( $\bar{x}=4.12)$, 'online shopping enable me to do my shopping quickly' ( $\bar{x}=3.43$ ), and 'online shopping is a good idea' ( $\bar{x}=3.36$ ). The five items that make up this factor revealed that online shopping offers the users time saving expediency, coupled with owing to the ubiquous nature of the online shopping facility (Ali et al., 2010; Ward, 2008). Convenience, therefore, refers to time savings and effort savings that include reduced physical and mental effort when shopping online (Jen-Hung \& Yi-Chun, 2010). This is because consumers consider online shopping makes it easy for them to locate suppliers (Jen-Hung \& Yi-Chun, 2010), find product items and procure various offerings (Childers et al., 2001; Balasubramanian, 1997), without having to leave their homes (Wolfinbarger \& Gilly, 2003). The inclusion of this factor demonstrates that the respondents consider convenience as playing a significant role in their decision to shop or make purchases online. In concert with these findings, Richa (2012) dubbed this factor this biggest qualitative gain of online shopping, alongside wider choice, home delivery and flexibility.

The second factor, perceived security (eigenvalue $=2.823$ ), explained 14.1 percent of the total post-rotation variance. In addition, high factor loadings were obtained on this sub-scale (.581 $\leq \mathrm{PS}$ factor loadings $\leq .856)$ as well as

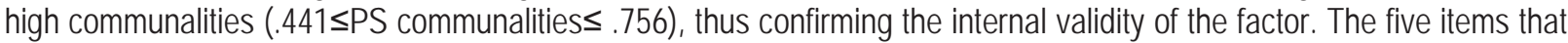
make up this factor were reverse coded in order to capture the full essence of the risks associated with shopping online. These included, 'my personal information may not be safe when shopping online' ( $\bar{x}=3.61)$, 'my credit card information 
may be stolen' ( $\bar{x}=3.69$ ), 'I have to wait for goods to be delivered' ( $\bar{x}=4.16)$, 'quality of products delivered may not be the same as one ordered' ( $\bar{x}=3.85$ ) and 'it can be difficult to return the defective product' ( $\bar{x}=3.89$ ). Security is defined as the extent to which consumers believe that making online purchases is secure (Vijayasarathy, 2004). It is related closely to privacy risks, which are concerned with consumers' personal information, credit card details, as well as their browsing and shopping habits and the possibility for the misuse of information. Therefore, to increase online shopping, merchants need to take proactive steps to minimise the consumer's feeling of risk (Cho \& Jialin, 2008). One method of doing that is building of consumer trust in the online store, a construct that is widely researched in technology acceptance studies. For example, financial security may be provided by safeguarding the consumers' personal data as well as providing alternative, secure payment methods such as PayPal, electronic funds transfer, and eBucks.

The third factor, perceived ease of use (eigenvalue $=1.522$ ), explained 7.6 percent of the total post-rotation variance. In addition, high factor loadings were obtained on this sub-scale (.645 $\leq$ PEOU factor loadings $\leq .757$ ), as well as high communalities $(.517 \leq$ PEOU communalities $\leq .611)$, thus confirming the internal validity of the factor. The four items that loaded on this factor were, 'I think I can shop online without any need for assistance' ( $\bar{x}=3.36)$, 'I think Internet shopping requires less effort on my part' ( $\bar{x}=3.55)$, 'I think I can shop online without encountering any problems' ( $\bar{x}$ $=2.79$ ), and 'I think online shopping is easy to use' ( $\bar{x}=3.37$ ). The items that make up this factor demonstrate that consumers are motivated to shop online if the degree of physical, mental and learning effort that is associated with the shopping experience is condensed. It appears, therefore, that technical aspects such as Internet connectivity, shorter loading times, and easier navigation across the network pages tend to determine the level of participation in the fantasy football games.

The fourth factor, perceived benefits (eigenvalue $=1.11$ ), explained 5.8 percent of the total post-rotation variance. In addition, high factor loadings were obtained on this sub-scale (.595 $\leq \mathrm{PB}$ factor loadings $\leq .793)$ as well as high communalities (.543 $\leq$ PB communalities $\leq .655)$, thus confirming the internal validity of the factor. Item reduction and scale purification led to only three items loading well on this construct, namely 'online shopping makes it easy to compare various products and brands' ( $\bar{x}=3.62)$, 'I can get better prices' ( $\bar{x}=2.88$ ), and 'I can find a greater variety of products and models online' ( $\bar{x}=3.57$ ). The three items that make up this factor indicate the importance of an effortless product acquisition and price comparison process, while using online shopping. The items on this factor have been validated in previous studies that have been conducted by Eastin (2002).

\section{Independent T-Tests for Differences (Online Shopping Factors with Gender)}

Independent sample t-tests were conducted with a view to identify any possible gender-based differences among the respondents, with regard to their decisions to participate in online shopping. Table 4 presents the results. Significant differences were noted with regard to the security factor $(p<0.05)$ with gender, while no gender-based, mean differences ( $p>0.05$ ) could be established along the other three factors, namely convenience, ease of use, and benefits.

Table 4: Test for differences between means: Online shopping factors and gender

\begin{tabular}{|l|c|c|c|c|c|c|c|c|}
\hline \multirow{2}{*}{ Online Shopping factor } & \multicolumn{2}{|c|}{ Male (N=117) } & \multicolumn{2}{c|}{ Female (N=140) } & \multicolumn{4}{c|}{ Test for differences } \\
\cline { 2 - 9 } & Mean & SD & Mean & SD & F & DF & T & Sig (P-value) \\
\hline Perceived convenience & 19.6752 & 3.53755 & 19.5929 & 3.58634 & .372 & 255 & .018 & .854 \\
\hline Perceived security & 18.4736 & 4.04198 & 19.7829 & 3.82537 & .226 & 255 & 2.00 & $.046^{*}$ \\
\hline Perceived ease of use & 12.9658 & 3.29297 & 13.1643 & 2.96408 & .171 & 255 & -.50 & .615 \\
\hline Perceived benefits & 10.0513 & 2.43483 & 10.0857 & 2.33979 & .259 & 255 & -.11 & .908 \\
\hline \multicolumn{4}{|c|}{ *Significant at p <0 .05 } \\
Minimum value (1) = strongly disagree; Maximum value (5) = strongly agree \\
\hline
\end{tabular}

The results of the independent sample t-tests revealed that there were no significant differences regarding the convenience dimension $(F=.372 ; t=.018 ; p>0.05)$ between male and female participants. This indicates that in this study, there are no differences relating to the level with which males and females view the importance of convenience as a main objective for conducting online shopping activities. Interestingly, the results of this study are at variance with previous studies, which established that owing to their task-oriented nature, males favour shopping convenience, which is explained as the ability to shop almost anytime from a variety of locations without visiting a store, when compared to their female counterparts (Khare \& Rekesh, 2011; Rodgers \& Harris, 2003). The surprising results of this study are in direct contrast with Hanson (2010) who posits that men exhibit higher levels of goal-directedness (compared to women) in their online shopping behaviour, and therefore, will look out for shopping avenues that will enable them to save time and be 
flexible. It appears then that both male and female students perceive online shopping as being practical and convenient. The notable finding in the current study could be explained by the cross-cultural invariance of the scale that was used, as well as the unique student sample that was surveyed.

With regard to the security dimension, statistically significant differences were noted $(F=.226 ; t=2.00 ; p<0.05)$ between male $(M=18.47, S D=4.04)$ and female $(M=19.78, S D=3.82)$ participants. Information systems studies have supported the notion that there are gender differences in the context of individual adoption and sustained usage of technology (Venkatesh \& Morris, 2000). Women were reported to have a higher level of web apprehensiveness, inter alia resistance to or fear of using the Internet as a channel for context-free online purchases (Susskind, 2004). Khare and Rakesh (2011) found that females perceived more risk when shopping online than males, as such their desire for online security is more profound. Studies of Cho and Jialin (2008) pointed out that females are less likely to trust online shopping as compared to their female counterparts. In addition, previous studies have indicated that men show more positive cognitive and behavioural attitudes than those of females, suggesting that men are more confident while shopping online than females (Chou et al., 2010; Garbarino \& Strahilevitz, 2004; Hanson, 2010; Venkatesh \& Morris, 2000). Notably, web-store software developers ought to pay more attention to online security features such as secure payment options, secure servers and certificates assuring integrity of data transfer, with a view to enhance the trust factor among respondents, more especially the female online shoppers.

The results on the t-tests further revealed that there were no statistically significant differences regarding the ease of use dimension $(F=.171 ; t=-.50 ; p>0.05)$ with gender. In view of the fact that user-friendliness is fundamental when developing online web-stores, there were no significant differences noted regarding the influence of ease of use on online shopping participation among students. This is contrary to the studies of Chou et al. (2010) who suggest that men are more likely to find online shopping websites easy to navigate, while women are cautious and find the online shopping websites generally difficult to navigate. Perhaps online merchants have taken considerable measures to eliminate the physical and emotional hassles associated with online shopping such that these aspects have become a matter of no consequence to either men or women when making purchases through the Internet.

The results on the t-tests further revealed that there were no statistically significant differences regarding the benefits dimension ( $F=.259 ; t=-.11 ; p>0.05)$ with gender. This finding is contrary to the study by Hanson (2010) who highlighted that women prefer physically to search for products and look out for bargains, while shopping on both traditional and non-traditional formats. Future studies may try to investigate the trade-off between perceived benefits and risks, culminating with online shopping value for both male and female student shoppers.

\section{Strengths, Limitations and Further Research}

The strength of the present study lies in its exploratory nature and application over a student consumer segment. This constitutes an important source of fresh knowledge on the underlying factors that influence the online activities of university students, in particular. However, the study has a limitation in that its results are restricted to South African shoppers only. Furthermore, although the sample size of 256 respondents may have been adequate for inferential statistical analysis, it may not present a true representation of the prominence of online shopping, nationally. This implies that caution must be exercised when generalising the results to other geographical locations and upon deriving subsequent conclusions from this study. Therefore, a replication of this study in other provinces, cultures and market segments, utilising better sampling methods, is warranted in order to establish the robustness of the scale for cumulative research. More research may be conducted in different contexts to explore the linkages among the constructs used in this study with a view to determine a scale, which possesses clinical utility, for use in future online shopping acceptance related studies. In addition, a randomised sample may be utilised with a view to confirm the efficacy of the constructs that have been identified in this study.

\section{Conclusions and Recommendations}

As online shopping is still a growing phenomenon, it is crucial for marketers to understand the factors underlying students' online shopping behavior. The spending power of students has overtaken those of their parents. Students also spend more time on the Internet, which is more likely to influence their future online shopping behaviour. This research has identified convenience as the most important dimension that influences students' online shopping behaviour Marketers could thus focus on these dimensions when targeting the students. They could ensure that their websites are designed such that they could save students' time and effort.

The students' online shopping behavior is also influenced by their perceptions of online transaction security. Male 
and female students differed on perceived security associated with online shopping. However, they did not differ on other dimensions such as perceived convenience, perceived ease of use and perceived benefits. This implies that marketers could emphasise the security dimension when marketing to females, since they demonstrate higher levels of riskaversion and security fears regarding the Internet, than males (Susskind, 2004). Marketers could introduce novel payment methods such as PayPal and electronic money vouchers to ensure that online purchases are secure. Other alternative payment methods could include a cash-on-delivery strategy to alleviate fears of credit card information leaking, telegraphic/wired transfers, billing to mobile phones and landlines, direct debit, gift cards and postal money orders. Similarly, there has been a proliferation of alliances between retailers with financial institutions on reward programmes such as eBucks and greenbacks, which operate as loyalty-based monetary schemes. In addition, the issues relating to privacy and protection of customers' information cannot be ignored when operating along online platforms. . Marketers could also ensure that the e-retailer's privacy policy as well as vendor address is protected using Secure Socket Layer (SSL) encryption when entering credit card information. Furthermore, quality seals could be used on the shop web-page in an effort to increase consumer confidence of the online shoppers.

\section{References}

Ali, P., Sankaran, S. \& Stevrin, P. (2010). Online Shopping: Customer satisfaction and loyalty in Norway. Thesis submitted in partial fulfillment of the degree Masters in Business Administration. Norway: Blekinge Tekniska Hogskola.

Alreck, P. \& Settle, R. B. (2002). Gender effects on Internet, catalogue and store shopping. Journal of Database Marketing, 9(2), 150-162.

Babin, B. J., Darden, W. R. \& Griffin, M. (1994). Work and/or fun: measuring hedonic and utilitarian shopping value. Journal of Consumer Research, 20(4), 644-656.

Balasubramanian, S. (1997). Two essays in direct marketing. Ph.D. Dissertation, Yale University, New Haven, CT. United States of America.

Brashear, T., Kashyap,V., Musante, M. \& Donthu, N. (2009). A profile of the Internet shopper: evidence from six countries. Journal of Marketing Theory and Practice, 17(3), 267-289.

Campbell, D. J. (1988). Task complexity: a review and analysis. Academy of Management Review, 13(1), 40-52.

Cant, M. C. \& Machado. R. (2005). Marketing success stories. (5th ed). Cape Town: Oxford.

Chaston, I. (2000). Entrepreneurial marketing; competing by challenging conventions. London: Macmillan Business Press.

Chen, S. Y. \& Macredie, R. D. (2005). The assessment of usability of electronic shopping: a heuristic evaluation. International Journal of Information Management, 25(1), 516-532.

Childers, T.L., Cristopher, C.L., Peck, J., \& Carson, S. (2001). Hedonic and utilitarian motivations for online retail shopping behaviour. Journal of Retailing, 77(1), 511-535.

Chiu,Y. B., Lin, C. P. \& Tang, L. L. (2005). Gender differs: assessing a model of online purchase intentions in e-tail services. International Journal of Service Industry Management, 16(5), 419-435.

Cho, H. \& Jialin, S. K. (2008). Influence of gender on Internet commerce: an explorative study in Singapore. Journal of Internet Commerce, 7(1), 95-119.

Churchill G. A. (Jr) \& lacobucci D. (2002). Marketing research: methodological foundations. (8th ed.). Fortworth: Harcourt College Publishers.

Chou, C., Wu, H.-C. \& Chen. C.-H. (2010). Re-visiting college students' attitudes toward the Internet-based on a 6-T model: gender and grade level difference. Computers and Education, 56(1), 939-947.

Clemes, M. D., Gan, C. \& Zhang, J. (2014). An empirical analysis of online shopping adoption in Beijing, China. Journal of Retailing and Consumer Services, 21(2014), 364-375.

De Swardt, M. \& Wagner, C. (2008). Factors influencing the choice to shop online: a psychological study in a South African context. New Voices in Psychology, 4(2), 68-82.

Donthu, N. \& Garcia, A. (1999). The Internet shopper. Journal of Advertising Research, 39(3), 52-58.

Eastin, M. S. (2002). Diffusion of E-commerce: an analysis of the adoption of four E-commerce activities. Telematics and Informatics, 19(3), 251267.

Falk, L. K., Sockel, H. \& Chen, K. (2005). E-commerce and consumer 's expectations: what makes a website work. Journal of Website Promotion, $1(1), 65-75$

Field A. (2005). Discovering statistics using SPSS. (2nd ed.). London: Sage Publishers.

Garbarino, E. \& Strabilevitz, M. (2004). Gender differences in the perceived risk of buying online and the effects of receiving a site recommendation. Journal of Business Research, 57(1), 768-775.

Ha, S. \& Stoel, L. (2009). Consumer e-shopping acceptance: antecedents in a technology acceptance model. Journal of Business Research, 62(5), 565-571.

Hanson, B. (2010). Exploring gender differences in online shopping attitude. Computers in Human Behavior, 26(1), 597-601.

Hasslinger, A., Hodzic, S. \& Opazo, C. (2007). Consumer behaviour in online shopping. Sweden: Kristianstad University. [Online] Available: http://www.projectsparadise.com /consumer-behaviour-online-shopping (January 24, 2013).

Hsiao, M. H. (2009). Shopping mode choice: physical store shopping versus e-shopping. Transportation Research Part E: Logistics and Transportation Review, 45(1),86-95.

Huang, M. (2000). Information load: its relationship to online exploratory and shopping behaviour. International Journal of Information Management, 20(1), 337-347.

Jarvenpaa, S. L. \& Todd, P. A. (1997). Consumer reactions to electronic shopping on the World Wide Web. International Journal of Electronic Commerce, 1(1), 59-88. 
Jen-Hung, H. \& Yi-Chun, Y. (2010). Gender differences in adolescents' online shopping motivations. African Journal of Business Management, $4(6), 849-857$

Khare, A., Khare, A., \& Singh, S. (2012). Attracting shoppers to shop online - challenges and opportunities for the Indian retail sector. Journal of Internet Commerce, 11(2), 161-185.

Khare, A. \& Rakesh, S. (2011). Antecedents of online shopping behavior in india: an examination. Journal of Internet Commerce, 10(4), $227-244$.

Kim, J. (2004). Understanding consumers' online shopping and purchasing behaviours. Thesis. Doctor of Philosophy. Oklahoma: Graduate College of Oklahoma State University.

Kim, J.-O. \& Mueller, C. W. (1978). Factor analysis: Statistical methods and practical issues. Beverly Hills, CA: Sage.

Koutras, E. (2006). The use of mobile phones by Generation Y students at two universities in the city of Johannesburg. Master's Dissertation. Pretoria: UNISA.

Lian, J. \& Lin, T. (2008). Effects of consumer characteristics on their acceptance of online shopping: comparisons among different product types. Computers in Human Behavior, 24(1), 48-65.

Liang, D. (2009). Critical factors influencing Taiwanese young adults' willingness to shop online. Web Journal of Chinese Management Review, 12(4), $1-23$.

Lian, J. \& Lin, T. (2008). Effects of consumer characteristics on their acceptance of online shopping: comparisons among different product types. Computers in Human Behavior, 24(1), 48-65.

Liao, Z. \& Cheung, M. T. (2001). Internet-based e-shopping and consumer attitudes: an empirical study. Information and Management, 38(5), 299-306.

Mehrabian, A. \& Russell, J. A. (1974). An approach to environmental psychology. Cambridge, MA: MIT Press.

Malhotra, N. K. (2010). Marketing research: an applied orientation. (6th ed.). New Jersey: Pearson Prentice-Hall.

Molesworth, M. \& Suorti, J. P. (2001). Buying cars online: the adoption of the Web for high involvement, high cost purchases. Journal of Consumer Behaviour, 2(2), 155-168.

Moodley, S. (2003). The challenge of e-business for the South African apparel sector. Technovation, 23, 557-570.

Nielsen Media Research Company. (2008). Global consumer attitudes towards online shopping. [Online]. Available: http://nielsen.com/ us/en/insights/press-room/2008/over_875_million_consumers.html (July 27, 2013).

Nunnally J. C. (1978). Psychometric theory. (2nd êd.). New York: McGraw Hill.

Nunnally J. C., Bernstein I. H. (1994). Psychometric theory. (3rd ed.). New York: McGraw Hill.

Organisation for Economic Co-operation and Development (OECD). (2007). Participative Web and user created content: Web 2.0, wikis and social networking. Paris.

O'Cass, A. \& T. Fenech. 2003. Web retailing adoption: Exploring the nature of Internet users Web retailing behaviour. Journal of Retailing and Consumer Services $10(2), 81-94$.

Pavlou, P. A. (2003). Consumer acceptance of electronic commerce: integrating trust and risk with the technology acceptance model. International Journal of Electronic Commerce, 7(3), 69-103.

Pillay, L., Hoosen, N., Wajoodeen, M., Fisher, V., Mseleku, A. \& Gqalo, M. (2012). What is the future for brick and mortar within the South African FMCG and clothing retail. Vulindlela Syndicate 5; Opening the Way. [Online] Available: www.wrseta.org. za/2012.../Vulindlela final_ Submitted_11_03_2013.d. (March 14, 2014).

Planting, S. (2012). SA's online retail explosion. [Online] Available: http://www.moneyweb.co.za/moneyweb-south-africa/sas-online-retailexplosion?sn=2009\%20Detail. (March 15, 2014).

Prasad, C. \& Aryasri, A. (2009). Determinants of shopper behaviour in E-tailing: an empirical analysis. Paradigm, 13(1), 73.

Ranganathan, C. \& Ganapathy, S. (2002). Key dimensions of business to consumer websites. Journal of Information Management, 39(6), 457465.

Richa, D. (2012). The impact of demographic factors of consumers on online shopping behaviour: a study of consumers in India. International Journal of Engineering and Management Sciences, 3(1), 43-52.

Rodgers, S. \& Harris, M. (2003). Gender and e-commerce: an exploratory study. Journal of Advertising Research, 43(3), 322-330.

Siddiqui, N., McColl, J., O'Malley, A. \& Birtwistle, G. (2003). Retailer and consumer perceptions of online fashion retailers: Web site design issues. Journal of Fashion Marketing and Management, 7(4), 345-355.

Slyke, C. V., Comunale, C. L. \& Belanger, F. (2002). Gender differences in perceptions of Web-based shopping. Communications of the ACM, 45(7), 82-86.

Smith, R., Deitz, G., Royne, M. B., Hansen, J. D., Grünhagen, M. \& Witte, C. (2013). Cross-cultural examination of online shopping behavior: a comparison of Norway, Germany and the United States. Journal of Business Research, 66(2013), 328-335.

Statistics South Africa. (2010). Report on retail trade industry. [Online] Available: http://www.statssa.gov.sa/publications.html (October 5, 2010).

Susskind, A. (2004). Electronic commerce and World Wide Web apprehensiveness: an examination of consumers' perceptions of the World Wide Web. Journal of Computer-Mediated Communication, 9(3), 46.

Venkatesh, V. \& Morris, M. G. (2000). Why don't men ever stop to ask for directions? Gender, social influence and their role in technology acceptance and usage behaviour. MIS Quarterly, 24(1), 115-139.

Verhagen, T., Boter, J. \& Adelaar, T. (2010). The effect of product type on consumer preferences for Website content elements: an empirical study. Journal of Computer Mediated Communication, 16(1), 139-170.

Vijayasarathy, L. R. (2004). Predicting consumer intentions to use online shopping: the case for an augmented technology acceptance model. Information and Management Journal, 41(2004), 747-62.

Ward, S. J. (2008). The consumer-perceived risk associated with the intention to purchase online. Dissertation submitted in partial fulfillment of the degree Master of Commerce. Cape Town: Stellenbosch University.

Wolfinbarger, M. \& Gilly, M. C. (2003). eTailQ: dimensionalizing, measuring and predicting eTail quality. Journal of Retailing, 79(3):183-198.

Zikmund, W. G. \& Babin, B. J. (2007). Exploring marketing research. (9th ed.). USA: Thomson South-Western Publishers. 